and was admitted. The following afternoon he was taken to the operating theatre in order that his condition might be thoroughly examined under an anæsthetic. His breathing at that time being consiclerably hampered by extensive swelling in the submaxillary region and of the tongue, the latter protruding somewhat between the teeth, I proceeded to administer chloroform by means of a drop bottle and Skinner's mask, very gradually and with a free supply of air. The patient appeared to take the anæsthetic well until the onset of the excitement stage, which, as Mr. Michels, who was standing by, remarked, took the form of a typical epileptic fit. I immediately withdrew the chloroform and in a few seconds the fit ceased, but with it respiration also, the patient quickly showing urgent signs of asphyxia. I advisod immediate tracheotomy, which Mr. Michels at once performed, with the result that on just compressing the chest regular respiration was restored. An examination of his mouth was then made and the patient put back to bed. Shortly afterwards, in the presence of Mr. Michels, the patient had another apparent epileptic, fit, and again two hours later a third, remaining after each in a semi-delirious condition. He, however, died early the following morning, Dec. 10th, apparently from heart failure. 'There was no history of epilepsy or Bright's disease. The urine was not examined on adinission as the patient did not pass any, having been without food or drink for some time previous to admission owing to difficulty in swallowing.

Post mortem the urine in the bladder was tested and found to contain one-fifth albumin, no sugar, and no blood; the kidneys were quite healthy, both to the naked eye and also microscopically; there were some congestion of the brain, odema of the lungs, and some old pleural adhesions; all the other organs were healthy. There were an abscess in the tongue and purulent cellulitis of the neck.

The case, to my mind, is interesting for the following reasons: (1) What was the nature of the fits? Were they epileptic or were they uræmic? (2) Was the asphyxia the result of the fit or was it simply due to the condition of the man's neck and mouth?

$$
\text { I am, Sirs, yours faithfully, }
$$

ALEX. H. BREWER,

Jan. 13th, 1905. Honorary Anxsthetist to the German Hospital.

\section{THE M.D. DEGREE OF THE UNIVERSITY OF ST. ANDREWS.}

To the Editors of THE LANCET.

SIRs, - My attention thas been drawn to a paragraph in THE LANCET of Dec. 17th, 1904, p. 1763. The last Scottish Universities Commission, which finished its sittings in 1897, abolished the old power of granting ten M.D. degrees a year to practitioners of 15 years' standing and 40 years of age which the University of St. Andrews previously enjoyed.

I am, Sirs, yours faithfully,

E. WAYMOUTH REID

Dean of the Faculty of Medicine, University of St. Andrews.

University College, Dundee, Jan. 11th, 1905.

\section{THE ROYAL ORTHOPADIC HOSPITAL. To the Editors of THE LANCET.}

SIRs,-My attention having been drawn to the fact that the name of the hospital has been omitted this year from the Medical Directory, notwithstanding the fact that I made the annual return to the publishers, I shall be glad if you will kindly find space for this letter in the next issue of your journal in order that your readers may not form any wrong impression from this omission.

The hospital, having disposed of its site in Oxford-street and Hanover-square and the amalgamation with the National Orthopædic Hospital of Great Portland-street having, through the initiative of King Edward's Hospital Fund for London, been decided upon, is occupying temporary premises at 55, Bolsover-street, W., in proximity to the National Orthopædic Hospital, where its work is being carried on as usual.

Last year there were 3732 attendances of out-patients ; and by arrangements with the National Orthopædic Hospital, 133 in-patients were admitted and treated by the medical staff of this hospital. This arrangement will continue in force until such time as the amalgamation can be brought about and the rebuilding of the premises for the combined hospitals commenced.-I am, Sirs, yours faithfully,

Jan. 18th, 1905.

\section{THE BENEFITS OF TARGE ENEMATA.}

\section{To the Editors of THE LANCET.}

STRS, - The recent pronouncement of an eminent surgeon with regard to the treatment of obstinate constipation by ablation of the large intestine induces me to send you this record of my own personal experience, thinking it may be of value to some of your readers. I am now in my seventyseventh year. In my early career when a medical student I contracted a very severe attack of dysentery at the time when cholera was very prevalent in London; and some years after on coming to London when greatly exhausted with work I was similarly seized and lost consciousness. The dysentery was most acute and I have a very vivid remem. brance of the treatment, prescribed by the late Sir William Gull-viz., large doses of ipecacuanha, which certainly relieved the agony, but nauseated me to such an extent that my remembrance shudders at it still. More than 15 years ago I began to notice that the evacuations were getting smaller and smaller and that the difficulty in gaining effectual relief was becoming serious. I had a long and trying experience with aperients, small doses of castor oil, sulphur, hyoscyamus or belladonna, with soap or colocynth, and aperient waters, but these at first all seemed to do well enough but they became fitful in their time of operation, and being engaged in a large practice this was exceedingly inconvenient and at last became an intolerable nuisance. Moreover, it became quite clear that the contraction of what I presumed to be cicatricial in respect of the history was getting tighter and this led me to consider whether dilatation from below might not prove a very simple and easy means of ridding myself of these daily discomforts. This was the commencement of my use of enemata. I began witb a pint of warm water the last thing at night, now more than 15 years ago. Before long $I$ found that this was insufficient and $I$ increased it to one and a half pints and then to two pints, and for some years lately some 56 to 60 ounces. I can always insure a good and complete relief of the bowels and generally I go to sleep about eleven o'clock and sleep till six. I manage to place myself in the posture as though I were lying down, so as to prevent the undue sagging of the intestine from the pressure of so large a quantity of fluid. After $I$ began to use the large injections I gradually noticed that I was enabled to part with larger motions and now one of somewhat larger size proves to me that the calibre of the intestine in the part affected still keeps a grip upon the moving mass. I have not been able to see in my own case the injury thought to result from large enemata. I think there are many advantages. The emptying of the bowel of flatus, of feculent matter, not always perhaps in cases of this nature of the most salubrious type, brings with it refreshing and abundant sleep, removes headaches, and leaves the mind and body clear for the work and thought of another day. I have so greatly benefited by this method myself that $I$ consider my lengthened experience of its value may be worthy the consideration of any who are contemplating the removal of their large intestine.

Jan. 17th, 1905.

I am, Sirs, yours faithfully,

\section{THE CAUSATION OF SEX.}

\section{Io the Editors of THE LANCET.}

SrRs,-The letter of "Medicus" in THE LANCET of Jan. 7th, p. 58, is not a solitary observation and his results are confirmed by other if less exact trials of the same general nature. There is little doubt that his observations are perfectly accurate so far as they go, but it is perhaps worth while to observe that there are two large factors which he does not mention though he has probably not overlooked them. He has been needlessly tender with the theory of the "predetermined" ovum.

Of these, the first is the relative age of the parents. It is a point of very considerable importance that the mother whose reproductive powers are senescent is extremely prone to produce male offspring only. This observation seems to be true not only of mammalia generally but also of aves; moreover, it is frequently seen to be true of homo and is a factor quite disassociated from any paternal factors. As a sort of corollary to this factor is the much less marked tendency of the immature sire to beget female issue. This tendency is less marked relatively but it is intrinsically evident enough and more 